\section{AIDS, HIV and the Sunday Times}

This letter was submitted for publication to the Sunday Times on 23 March this year, in response to an article published on 21 March. The newspaper declined to publish it. Professor Anderson is now in the Department of Zoology, University of Oxford.

SIR - Your article entitled "Epidemic of AIDS in Africa 'a tragic myth" gives a seriously misleading impression of the magnitude of the AIDS problem. You again give credence to the claims of Professor Peter Duesberg that HIV is not the cause of the disease AIDS. Last month, two carefully controlled studies of homosexual and heterosexual men in San Francisco (Nature 11 March 1993) and homosexual men in Vancouver (Lancet 13 March 1993) were published demonstrating that only those with evidence of HIV infection developed AIDS, and that in those infected with HIV, drug use is no more frequent in those who develop AIDS than in those who do not. Yet again, Duesberg's claims that drug use rather than HIV is a cause of the disease AIDS have been firmly rejected.

More broadly, your article appears to present two lines of argument. First that the high prevalences of HIV observed in various parts of Africa do not reflect a major AIDS epidemic; and second, that the high prevalences reported in the medical and scientific literature are false and unrepresentative of the true picture. Your correspondent draws these conclusions on the basis of a 2-month study by a television presenter, Joan Shenton. He fails to mention the many years of study by experts and highly qualified scientists and epidemiologists, whose work has been peer-reviewed and published in leading scientific and medical journals, that totally contradicts the non-expert opinion of Shenton. The evidence charting the emergence and rapid growth of the AIDS epidemic in Africa (and other regions of the developing world) over the past 12 years is detailed in hundreds of scientific publications. In the worst-afflicted countries in Africa the prevalence of HIV infection in the sexually active population has risen to $20-40 \%$ in some urban centres. As a direct consequence of the immunodeficiency caused by HIV infection, the prevalences of other killer diseases such as tuberculosis have also been rising in many regions. Persistent tuberculosis infection in HIV-infected individuals also acts to spread tuberculosis to those not infected with HIV.

Your correspondent cites a Dr H. Bialy who states that most HIV-positive tests are false in Africa because of the presence of malaria in many patients. In 1985 an association between malaria and the likelihood of getting a positive HIV test result was reported. However, much sub- sequent work with the current generation of highly reliable HIV tests (virtually $100 \%$ specific) has found no association between present or past infection with malaria and the likelihood of getting a positive HIV test result. He also cites Professor Beverly Griffin, who reports very low levels of HIV infection $(1-2 \%)$ in Malawi, for further evidence of limited HIV spread in Africa. Griffin's results are based on small samples of 5-8-year-old children from rural regions. Current evidence from Africa suggests that $35 \%$ of infants born to infected mothers acquire HIV. Infected children have a short life expectancy in developing countries (a conservative estimate is 4 years from birth) and hence a $1-2 \%$ prevalence of HIV in 5-8-year-olds implies a $14-28 \%$ prevalence of HIV in pregnant women a number of years ago. Malawi is not a country from which data on the prevalence of HIV are readily available, but a study in 1990 in an urban setting of 6,482 pregnant women revealed a $22.8 \%$ prevalence of HIV infection. In much of Africa, the urban centres are the worst hit at present, but infection is steadily spreading into the rural areas.

Your article seriously undermines the efforts of many concerned scientists and medical personnel to persuade governments in Africa, and international aid agencies, of the urgency of trying to slow the spread of HIV. In some urban centres in Africa, AIDS is already the leading cause of adult mortality (for example Abidjan, Cote d'lvoire) and in the coming decade this trend is likely to be repeated in many other regions of the world. The research on the spread of AIDS and the mortality included by the epidemic in Africa is published in leading journals such as the Lancet, the British Medical Journal, Science and Nature. The basis of the views presented by the supposed experts cited in your article are less easy to validate. Much of the article relies on the views of $\mathrm{H}$. Bialy, who is associated with the journal Bio/technology. While Biol technology is a reputable journal in the field of biotechnology, it is a sister journal to Nature only in the sense that the Sun is a sister journal to the Sunday Times. A search for papers published by $\mathrm{H}$. Bialy in 1992 revealed one on transgenic wheat and another on pathway analysis in plant cells. If the Sunday Times's views about AIDS are to be seen as anything more than sensationalist, it should choose its "experts" more carefully.

\section{Geoff Garnett}

\section{Roy Anderson}

Department of Biology,

Imperial College,

London SW7 2BB, UK

\section{Calendar reform}

SIR - Jews reckon time from the biblical creation of the world (set at $3761 \mathrm{BC}$ ); the Romans from the founding of Rome; and the Moslems since the Hegira (AD 622). In AD 526, the Emperor Justinian introduced the current system of reckoning time from the birth of Christ, set at 753 AUC ( $a b$ urbe condita, "since the founding of Rome") by the monk Dionysius Exiguus.

In the BC/AD system that Justinian introduced, the numbering of years is ordinal, not cardinal; there is no year zero; and the numbers increase in opposite directions (whereas time flows in the same direction). As a result, time intervals across the BC/AD boundary cannot be calculated algebraically - the time interval between $1.5 \mathrm{BC}$ and $\mathrm{AD} 1.5$ is one year, not three years. As well as being inconvenient to those who deal with history and ancient human events, the BC/AD way of reckoning years singles out an event - the birth of Christ - that has no significance to many civilizations.

I propose that the beginning of calendrical time could be set at the beginning of the current Julian cycle $(12.00$ noon Greenwich mean time, 4713 BC), established in 1582 by Joseph Scaliger and still used by astronomers. A constant - 4,713 years - would then have to be added to the $\mathrm{AD}$ dates and the $\mathrm{BC}$ dates would have to be subtracted from 4714 (the Scaliger year equivalent to AD 1). (To simplify the arithmetic, a round unit such as 10,000 years could be added to the AD dates instead.)

Setting the birth of Christ at 25 December of the year 10,000 from the beginning of what could be appropriately called the "human era", would make the year AD 1 into the year 10,001 and the year $1 \mathrm{BC}$ into the year 10,000 . All BC dates would thus be subtracted from 10,001 .

Setting the beginning of the human era at $10,000 \mathrm{BC}$ would date the first year of Scaliger's Julian period at the year 5288; the beginning of the Egyptian calendar $(4241 \mathrm{BC}$ ) at the year 5760 ; the founding of Rome at 9248 , the birth of Christ at 10,000 , the fall of the Roman Empire at 10,476, the French Revolution at 11,789 and the present year (1993) at 11,993 . I suggest that the new calendar is adopted in the year 2000 (new year 12,000).

\section{Cesare Emiliani}

Department of Geological Sciences,

University of Miami,

Coral Gables,

Florida 33124, USA

\section{Correction: FGIN}

- A letter in Correspondence about the Fidia Georgetown Institute for the Neurosciences (Nature 366, 399; 1993) should have included among the signatories the following: Pier Franco Spani (Chairman, Institute of Pharmacology, University of Brescia). 